\title{
Teores de nutrientes da folha bandeira e grãos de aveia-preta em função da adubação fosfatada e postássica
}

\author{
Nutrients concentrations in the flag leaf and grains of black-oat \\ affected by phosphate and potassium fertilization
}

\author{
João Nakagawa ${ }^{1}$; Carlos Alexandre Costa Crusciol' ${ }^{2}$ Claudemir Zucareli ${ }^{3 *}$
}

\section{Resumo}

\begin{abstract}
A aveia-preta (Avena strigosa Schreber) tem sido comumente utilizada para adubação verde, rotação de culturas no sistema de plantio direto, em cultivo no outono-inverno e ainda, para pastejo, fenação e ensilagem. O objetivo deste trabalho foi avaliar os teores de macro e micronutrientes da folha bandeira e dos grãos de aveia-preta cv. Comum em função da adubação fosfatada e potássica. O experimento foi realizado em condições de campo, em Nitossolo Vermelho, em Botucatu-SP. Os tratamentos constaram de três doses de superfosfato simples $\left(0,40\right.$ e $80 \mathrm{~kg} \mathrm{ha}^{-1}$ de $\left.\mathrm{P}_{2} \mathrm{O}_{5}\right)$ e três doses de cloreto de potássio $\left(0,20\right.$ e $40 \mathrm{~kg} \mathrm{ha}^{-1}$ de $\left.\mathrm{K}_{2} \mathrm{O}\right)$ dispostos em esquema fatorial (3 $\mathrm{x} 3$ ), sob o delineamento de blocos casualizados, com quatro repetições. A adubação foi feita no sulco de semeadura. Em todas as parcelas foi aplicado sulfato de amônio, sendo $20 \mathrm{~kg} \mathrm{ha}^{-1}$ de $\mathrm{N}$ na semeadura e $30 \mathrm{~kg} \mathrm{ha}^{-1} \mathrm{em}$ cobertura no final do perfilhamento. Os teores de $\mathrm{Ca}, \mathrm{Mg}, \mathrm{S}, \mathrm{Fe}, \mathrm{Mn}, \mathrm{Cu}$ e $\mathrm{Zn}$ da folha bandeira e de $\mathrm{P}$ e $\mathrm{K}$ dos grãos foram influenciados pela adubação fosfatada. A adubação potássica não influenciou os teores de macro e micronutrientes da folha bandeira e dos grãos em aveia preta.
\end{abstract}

Palavras-chave: Avena strigosa, fósforo, potássio, macronutrientes, micronutrientes

\begin{abstract}
The black oat (Avena strigosa Schreber) has been commonly used as green manure, in crop rotation systems under no-tillage, fall-winter crop, and for cattle grazing, hay, and silage. The objective of this work was to evaluate the nutrient concentrations in the flag leaf and grains of black-oat affect by phosphate and potassium fertilization. The experiment was carried out under field conditions on a Rhodic Nitosol, in Botucatu, São Paulo State, Brazil. Three doses of single superphosphate $(0,40$ and 80 kg.ha ${ }^{-1}$ of $\left.\mathrm{P}_{2} \mathrm{O}_{5}\right)$ and three of potassium chloride $\left(0,20\right.$ and $40 \mathrm{~kg} \mathrm{ha}^{-1}$ of $\left.\mathrm{K}_{2} \mathrm{O}\right)$ were tested as a factorial ( $3 \times 3)$, in a randomized complete block design, with four replicates. The fertilizers were applied in the sowing row. Ammonium sulphate was supplied for all plots $\left(20 \mathrm{~kg} \mathrm{ha}^{-1}\right.$ of $\mathrm{N}$ applied at sowing and 30 kg.ha ${ }^{-1}$ after tillering stage). The concentrations of $\mathrm{Ca}, \mathrm{Mg}, \mathrm{S}, \mathrm{Fe}, \mathrm{Mn}, \mathrm{Cu}$ and $\mathrm{Zn}$ in the flag leaf and the $\mathrm{P}$ and $\mathrm{K}$ concentrations in the grain were increased by phosphate fertilizer application. The potassic fertilization had no effect on the concentrations of nutrients in the flag leaf and grains of black-oat.

Key words: Avena strigosa, phosphate, potassium, macronutrients, micronutrients
\end{abstract}

1 Prof. Titular aposentado, voluntário. Depto. de Produção Vegetal - Faculdade de Ciências Agronômicas, UNESP. Cx. Postal 237, CEP:18603-970, Botucatu-SP.

2 Prof. Adjunto. Depto. de Produção Vegetal - Faculdade de Ciências Agronômicas - UNESP/Botucatu-SP. Bolsista do CNPq.

3 Prof. Adjunto. Depto. Agronomia, Centro de Ciências Agrárias, UEL. Cx. Postal 6001, CEP:86051-990, Londrina-PR. e-mail: claudemircca@uel.br.

* Autor para correspondência 


\section{Introdução}

A aveia-preta (Avena strigosa Schreber) é uma gramínea, anual pouco exigente em fertilidade do solo, resistente a moléstias, utilizada para adubação verde e como planta de cobertura para plantio direto em sistemas de rotação de culturas, no outonoinverno (DERPSCH; CALEGARI, 1992; WUTKE, 1993). É, ainda, empregada para pastejo, fenação e, ensilagem, sendo os grãos utilizados na formulação de concentrados para animais (DERPSCH; CALEGARI, 1992).

Os trabalhos de adubação de aveia-preta, realizados em condições brasileiras, com nitrogênio (N) (NAKAGAWA; CAVARIANI; MACHADO, 1995, 2000; SCHUCH et al., 1999; SILVA et al., 2001), fósforo (P) e potássio (K) (NAKAGAWA; CAVARIANI; BICUDO, 2003; RODRIGUES; WOLKWEISS; ANGHINONI, 1985) têm mostrado respostas positivas para produção de massa e/ ou de sementes/grãos, à semelhança do que tem ocorrido para aveia-branca (KELLING; FIXEN, 1992; FORSBERG; REEVES, 1995; PRIMAVESI; PRIMAVESI, 1996; CECCON; GRASSI FILHO; BICUDO, 2004).

Nos trabalhos com adubação de aveia-preta são, comumente, avaliados a produtividade, os componentes de produção e a qualidade fisiológica das sementes, mas aqueles que estudaram os efeitos sobre os teores de nutrientes nas folhas e nos grãos são poucos (RODRIGUES; WOLKWEISS; ANGHINONI, 1985; NAKAGAWA; ROSOLEM, 2005). Estudos que visam o conhecimento do conteúdo de nutrientes das plantas, principalmente da parte colhida, são importantes pois permitem determinar a quantidade de nutrientes exportados da área cultivada enquanto, a avaliação do teor de nutrientes na folha diagnose possibilita avaliar o estado nutricional das plantas.

O objetivo do trabalho foi verificar o efeito da adubação fosfatada e potássica sobre os teores de macro e micronutrientes na folha bandeira e nos grãos de aveia-preta.

\section{Material e métodos}

O trabalho foi realizado com aveia-preta cv. comum, em condições de campo, em solo classificado como Nitossolo Vermelho (OLIVEIRA et al., 1999), pertencente à Fazenda Experimental Lageado (FEL) do Campus de Botucatu-UNESP, localizado no município de Botucatu, com altitude de $815 \mathrm{~m}$, latitude de $22^{\circ} 51^{\prime} \mathrm{S}$ e longitude de $48^{\circ} 26^{\prime}$ 'WGrw. A análise química do solo (RAIJ; QUAGGIO, 1983), realizada antes da instalação do experimento, apresentou os seguintes resultados: 4,5 unidades de $\mathrm{pH}$ em $\mathrm{CaCl}_{2}, 34 \mathrm{~g} \mathrm{dm}^{-3}$ de M.O., $11 \mathrm{mg} \mathrm{dm}^{-3}$ de $\mathrm{P}$ (resina), 2,2, 11,2, 6,7 e 80 mmolc $\mathrm{dm}^{-3}$ de $\mathrm{K}, \mathrm{Ca}, \mathrm{Mg}$ e $\mathrm{H}+\mathrm{Al}$, respectivamente, e $20 \%$ de saturação por base, na profundidade de zero a $20 \mathrm{~cm}$. Os dados referentes às precipitações pluviais no período do trabalho foram coletados no posto meteorológico da FEL.

Dois meses antes da semeadura, foi feita a calagem, baseando-se nos resultados da análise química do solo e nas recomendações encontradas em Raij et al. (1996). Foram aplicados 2,5 t ha ${ }^{-1}$ de calcário dolomítico objetivando elevar a saturação por base a $50 \%$.

OExperimento foi conduzido como delineamento em blocos casualizados, disposto em esquema fatorial $3 \times 3$ com quatro repetições. Os fatores estudados foram três doses de fósforo, superfosfato simples $\left(\mathrm{SS}_{0}=0, \mathrm{SS}_{1}=40, \mathrm{SS}_{2}=80 \mathrm{~kg} \mathrm{ha}^{-1}\right.$ de $\left.\mathrm{P}_{2} \mathrm{O}_{5}\right)$ e três doses de potássio, cloreto de potássio $\left(\mathrm{CP}_{0}=0\right.$, $\mathrm{CP}_{1}=20, \mathrm{CP}_{2}=40 \mathrm{~kg} \mathrm{ha}^{-1}$ de $\mathrm{K}_{2} \mathrm{O}$ ). Em todos os tratamentos foi aplicado sulfato de amônio, na dose de $50 \mathrm{~kg} \mathrm{ha}^{-1}$ de $\mathrm{N}$, sendo $20 \mathrm{~kg} \mathrm{ha}^{-1}$ na semeadura, juntamente com os adubação fosfatada e potássica, e $30 \mathrm{~kg} \mathrm{ha}^{-1} \mathrm{em}$ cobertura no final do perfilhamento das plantas.

As parcelas constaram de dez linhas de seis metros de comprimento, com espaçamento de $0,2 \mathrm{~m}$ entrelinhas. Na colheita foram desprezadas, como bordaduras, as linhas externas e $0,5 \mathrm{~m}$ de cada extremidade das oito linhas centrais, resultando em $8,0 \mathrm{~m}^{2}$ de área útil. A semeadura foi realizada 
manualmente, na densidade de 40 sementes por metro. O controle das plantas daninhas foi feito manualmente.

$\mathrm{Na}$ emergência das panículas foram amostradas ao acaso, 70 folhas bandeiras por tratamento e por repetição conforme Cantarella, Raij e Camargo (1996), para avaliação dos teores de macro (N, P, K, $\mathrm{Ca}, \mathrm{Mg}$ e S) e micronutrientes (Fe, Mn, Cu, B e Zn) e da massa da matéria seca da folha. Os teores foram determinados de acordo com os métodos descritos por Malavolta, Vitti e Oliveira (1989).

A colheita dos grãos foi realizada quando $100 \%$ das panículas encontravam-se em ponto de colheita. Nos grãos foram determinados a massa de mil grãos (BRASIL, 1992) e os teores de macro e micronutrientes (MALAVOLTA; VITTI; OLIVEIRA, 1989).

Os dados foram submetidos à análise de variância e as média comparadas pelo teste de Tukey a 5\%. Foram realizados estudos de correlação linear simples entre os teores de nutrientes e a massa seca da folha bandeira e a massa de 1000 grãos, e entre os teores de nutrientes na folha bandeira e nos grãos.

\section{Resultados e discussão}

O solo utilizado apresentou teor de fósforo baixo, teores de potássio e de magnésio médios, o de cálcio alto, enquanto a acidez estava muito elevada e a saturação por bases muito baixa (RAIJ et al, 1996). Nas parcelas que não receberam a adubação fosfatada foi constatado aumento no ciclo das plantas, ocasionado pelo atraso no florescimento (emissão de panículas), que é um dos sintomas de deficiência de fósforo (MALAVOLTA; VITTI; OLIVEIRA, 1989).

Os teores de N, P e K nas folhas bandeiras não foram afetados pela adubação fosfatada e potássica (Tabela 1), apesar do solo apresentar baixo teor de fósforo e médio de potássio. Entretanto, como a massa de matéria seca da folha bandeira aumentou na presença do adubo fosfatado (Tabela 3), pode-se inferir que houve maior absorção e acúmulo destes três macronutrientes, nos tratamentos que receberam o superfosfato simples $\left(\mathrm{SS}_{1}\right.$ e $\left.\mathrm{SS}_{2}\right)$. Contribui com essa inferência, o fato do aumento da massa seca da parte aérea das plantas, sem contabilizar os grãos, ter sido na média desses tratamentos $76,7 \%$ superior em relação ao tratamento sem adubação fostatada (NAKAGAWA; CAVARIANI; BICUDO, 2003).

Tabela 1. Média dos teores de N, $\mathrm{P}, \mathrm{K}, \mathrm{Ca}, \mathrm{Mg}, \mathrm{Fe}, \mathrm{Mn}, \mathrm{Cu}$ e B, da folha bandeira de aveia-preta em função das doses de superfosfato simples $\left(\mathrm{SS}_{0}, \mathrm{SS}_{1}, \mathrm{SS}_{2}\right)$ e cloreto de potássio $\left(\mathrm{CP}_{0}, \mathrm{CP}_{1}, \mathrm{CP}_{2}\right)$.

\begin{tabular}{|c|c|c|c|c|c|c|c|c|c|}
\hline Tratamentos & $\mathrm{N}$ & $\mathrm{P}$ & K & $\mathrm{Ca}$ & $\mathrm{Mg}$ & $\mathrm{Fe}$ & $\mathrm{Mn}$ & $\mathrm{Cu}$ & B \\
\hline & & & $\mathrm{g} \mathrm{kg}^{-1}$ & & & \multicolumn{4}{|c|}{$\mathrm{mg} \mathrm{kg}^{-1}$} \\
\hline $\mathrm{SS}_{0}$ & 39,93 & 1,97 & 12,02 & $8,88 \mathrm{~b}$ & $1,72 \mathrm{~b}$ & $180,8 \mathrm{~b}$ & $214,1 \mathrm{~b}$ & $12,1 \mathrm{~b}$ & 20,4 \\
\hline $\mathrm{SS}_{1}$ & 39,60 & 2,06 & 12,03 & $14,14 \mathrm{a}$ & $2,02 \mathrm{a}$ & 216,2 a & $335,8 \mathrm{a}$ & $17,7 \mathrm{~b}$ & 22,8 \\
\hline $\mathrm{SS}_{2}$ & 38,73 & 2,14 & 12,16 & $13,53 \mathrm{a}$ & $1,89 \mathrm{ab}$ & $224,1 \mathrm{a}$ & 332,6 a & $26,0 \mathrm{a}$ & 23,0 \\
\hline $\mathrm{CP}_{0}$ & 39,94 & 2,11 & 11,65 & 12,73 & 1,96 & 206,2 & 288,7 & 19,9 & 21,4 \\
\hline $\mathrm{CP}_{1}$ & 39,05 & 2,04 & 11,88 & 12,08 & 1,86 & 212,0 & 298,7 & 19,0 & 22,9 \\
\hline $\mathrm{CP}_{2}$ & 39,28 & 2,01 & 12,68 & 11,74 & 1,82 & 202,8 & 295,1 & 16,8 & 21,8 \\
\hline C.V. $(\%)$ & 6,69 & 10,04 & 9,23 & 14,01 & 9,61 & 15,13 & 17,54 & 41,76 & 14,64 \\
\hline
\end{tabular}

Médias na coluna seguidas da mesma letra dentro de cada tratamento não diferem significativamente a 5\% de probabilidade pelo teste Tukey. 
Comparando os teores de $\mathrm{N}, \mathrm{P}$ e $\mathrm{K}$ na folha bandeira (Tabela 1), com as faixas consideradas adequadas para aveia (CANTARELLA; RAIJ; CAMARGO, 1996; KELLING; FIXEN, 1992), verificou-se que estão acima da faixa para $\mathrm{N}$ (faixa adequada de 20 a 30 g. $\mathrm{kg}^{-1}$ ), na faixa adequada para $\mathrm{P}$, em limite inferior (faixa adequada de 2,0 a 5,0 g. $\mathrm{kg}^{-1}$ ) e abaixo para $\mathrm{K}$ (faixa adequada de 15 a 30 g. $\left.\mathrm{kg}^{-1}\right)$.
Os teores de $\mathrm{Ca}, \mathrm{Mg}$ e $\mathrm{S}$ na folha bandeira foram influenciados pelo adubo fosfatado (Tabela 1 e 2) com menores valores para a dose zero $\left(\mathrm{SS}_{0}\right)$, enquanto entre $\mathrm{SS}_{1}$ e $\mathrm{SS}_{2}$ não houve diferença significativa nos teores, exceção ao teor de $\mathrm{S}$ quando na dose maior do adubo potássico (Tabela 2). A adubação potássica não aumentou os teores de $\mathrm{Ca}, \mathrm{Mg}$ e $\mathrm{S}$ da folha bandeira (Tabelas 1 e 2).

Tabela 2. Médias dos teores de $\mathrm{S}$ e $\mathrm{Zn}$, da folha bandeira de aveia-preta em função das doses de superfosfato simples $\left(\mathrm{SS}_{0}, \mathrm{SS}_{1}, \mathrm{SS}_{2}\right)$ e cloreto de potássio $\left(\mathrm{CP}_{0}, \mathrm{CP}_{1}, \mathrm{CP}_{2}\right)$.

\begin{tabular}{ccccccc}
\hline \multirow{2}{*}{ Tratamentos } & \multicolumn{3}{c}{$\mathrm{S}\left(\mathrm{g} \mathrm{kg}^{-1}\right)$} & $\left.\mathrm{CP} k g^{-1}\right)$ \\
\cline { 2 - 7 } & $\mathrm{CP}_{0}$ & $\mathrm{CP}_{1}$ & $\mathrm{CP}_{2}$ & $\mathrm{CP}_{0}$ & $\mathrm{CP}_{1}$ & $\mathrm{CP}_{2}$ \\
\hline $\mathrm{SS}_{0}$ & $2,65 \mathrm{~b}^{\mathrm{A}}$ & $2,60 \mathrm{~b}^{\mathrm{A}}$ & $2,22 \mathrm{c}^{\mathrm{A}}$ & $41,5^{\mathrm{B}}$ & $37,0 \mathrm{~b}^{\mathrm{B}}$ & $49,5^{\mathrm{A}}$ \\
$\mathrm{SS}_{1}$ & $4,52 \mathrm{a}^{\mathrm{A}}$ & $4,80 \mathrm{a}^{\mathrm{A}}$ & $3,85 \mathrm{~b}^{\mathrm{B}}$ & $42,8^{\mathrm{A}}$ & $46,5 \mathrm{a}^{\mathrm{A}}$ & $43,2^{\mathrm{A}}$ \\
$\mathrm{SS}$ & $4,48 \mathrm{a}^{\mathrm{AB}}$ & $3,62 \mathrm{ab}^{\mathrm{B}}$ & $5,50 \mathrm{a}^{\mathrm{A}}$ & $47,5^{\mathrm{A}}$ & $43,5 \mathrm{ab}^{\mathrm{A}}$ & $44,8^{\mathrm{A}}$ \\
\hline C.V. $(\%)$ & \multicolumn{5}{c}{8,77} & \\
\hline
\end{tabular}

Médias seguidas da mesma letra (minúscula na coluna para SS e, maiúscula na linha para CP) não diferem pelo teste Tukey a 5\%.

Tabela 3. Massa de matéria seca da folha bandeira (MMSFB) e massa de 100 grãos de aveia-preta em função das doses de superfosfato simples $\left(\mathrm{SS}_{0}, \mathrm{SS}_{1}, \mathrm{SS}_{2}\right)$ e cloreto de potássio $\left(\mathrm{CP}_{0}, \mathrm{CP}_{1}, \mathrm{CP}_{2}\right)$.

\begin{tabular}{ccc}
\hline Tratamentos & MMSFB $(\mathrm{mg})$ & Massa de 1000 grãos $(\mathrm{g})$ \\
\hline $\mathrm{SS}_{0}$ & $18,91 \mathrm{~b}^{(1)}$ & $18,62 \mathrm{~b}$ \\
$\mathrm{SS}_{1}$ & $29,96 \mathrm{a}$ & $19,94 \mathrm{a}$ \\
$\mathrm{SS}_{2}$ & $31,72 \mathrm{a}$ & $20,06 \mathrm{a}$ \\
& & \\
$\mathrm{CP}_{0}$ & 26,90 & 19,75 \\
$\mathrm{CP}_{1}$ & 27,16 & 19,37 \\
$\mathrm{CP}_{2}$ & 26,53 & 19,50 \\
\hline C.V. $(\%)$ & 10,43 & 2,44 \\
\hline
\end{tabular}

${ }^{1}$ Médias seguidas da mesma letra nas colunas não diferem pelo teste de TuKey a 5\%.

Os teores de $\mathrm{Ca}$ estão bem acima da faixa considerada adequada para aveia, de 2,5 a $5 \mathrm{~g}$ $\mathrm{kg}^{-1}$ (CANTARELLA et al., 1996), o que pode ser atribuído ao alto teor inicial desse nutriente no solo e à contribuição da calagem. Já os teores de $\mathrm{Mg}$ encontram-se na faixa adequada, de 1,5 a $5 \mathrm{~g}$ $\mathrm{kg}^{-1}$, provavelmente, como resultado da aplicação do calcário dolomítico. Os teores de $\mathrm{S}$ estão acima do considerado adequado, 1,5 a 4,0 g. $\mathrm{kg}^{-1}$, para alguns tratamentos com efeito de interação entre os superfosfato simples e o cloreto de potássio (Tabela 2); a adubação nitrogenada realizada com sulfato de amônio em todos os tratamentos pode ter auxiliado para estes resultados do enxofre, somando-se ao efeito do superfosfato simples que contribuiu para o aumento no teor da folha bandeira quando presente.

Os teores de $\mathrm{Fe}, \mathrm{Mn}$ e $\mathrm{Cu}$ da folha bandeira aumentaram com a adubação fosfatada (Tabela 
1) e, para os teores de $\mathrm{Zn}$ foi constatada interação significativa entre entre as adubações (Tabela 2). Com exceção ao $\mathrm{Zn}$, a adubação potássica não afetou os teores de micronutrientes (Tabela 1).

Os teores de $\mathrm{Cu}$ e $\mathrm{Zn}$ na folha bandeira estão dentro da faixa considerada adequada $(\mathrm{Cu}=5$ a 25 $\mathrm{mg} \mathrm{kg}{ }^{-1}$ e $\mathrm{Zn}=15$ a $70 \mathrm{mg} \mathrm{kg}^{-1}$ ), enquanto os de $\mathrm{Fe}$, $\mathrm{Mn}$ e B estão acima das faixas adequadas $(\mathrm{Fe}=40 \mathrm{a}$ $150 \mathrm{mg} \mathrm{kg}^{-1}, \mathrm{Mn}=25$ a $100 \mathrm{mg} \mathrm{kg}^{-1}$ e B $=5$ a $20 \mathrm{mg}$ $\mathrm{kg}^{-1}$ ) (CANTARELLA; RAIJ; CAMARGO, 1996).

A presença do superfosfato simples ocasionou aumentos na massa de matéria seca (Tabela 3) e nos teores $\mathrm{Ca}, \mathrm{Mg}, \mathrm{S}, \mathrm{Fe}, \mathrm{Mn}$ e $\mathrm{Cu}$ da folha bandeira (Tabelas 1 e 2), indicando que houve maior absorção e acúmulo destes nutrientes. A correlação encontrada entre a massa de matéria seca e os teores de nutrientes da folha bandeira (Tabela 5), que responderam à adubação fosfatada mostram a interrelação obtida entre aumento da massa e de absorção e acúmulo desses nutrientes, juntamente com o nutriente fósforo.
O aumento nos teores dos nutrientes da folha bandeira com a adubação fosfatada deve-se ao maior desenvolvimento das plantas proporcionado pela adição de fósforo em solo com baixo teor do elemento (NAKAGAWA; CAVARIANI; BICUDO, 2003), resultando em maior absorção e acúmulo de nutrientes. A dose de superfosfato simples $\left(\mathrm{SS}_{1}\right)$, calculada para $40 \mathrm{~kg} \mathrm{ha}^{-1}$ de $\mathrm{P}_{2} \mathrm{O}_{5}$, foi suficiente para ocasionar este efeito favorável, confirmando a menor exigência da aveia-preta (DERPCH; CALEGARI, 1992).

Os teores de P e K nos grãos (Tabela 4) foram influenciados pelas doses do superfosfato simples. A maior dose $\mathrm{SS}_{2}$ (equivalente a $80 \mathrm{~kg} \mathrm{ha}^{-1}$ de $\mathrm{P}_{2} \mathrm{O}_{5}$ ) resultou no maior teor de $\mathrm{P}$, enquanto as doses $\mathrm{SS}_{1} \mathrm{e}$ $\mathrm{SS}_{2}$ originaram teores superiores de $\mathrm{K}$. A adubação potássica não influenciou os teores de nutrientes dos grãos. Peterson; Schrader e Youngs (1974) concluíram que a quantidade de $\mathrm{P}$ e $\mathrm{K}$ acumulada nos grãos de aveia-branca varia em função das condições ambientais e da cultivar, enquanto o $\mathrm{Ca}$ é mais estável.

Tabela 4. Médias dos teores de N, P, K, Ca, Mg, S, Fe, Mn, Cu e Zn, dos grãos de aveia-preta em função das doses de superfosfato simples $\left(\mathrm{SS}_{0}, \mathrm{SS}_{1}, \mathrm{SS}_{2}\right)$ e cloreto de potássio $\left(\mathrm{CP}_{0}, \mathrm{CP}_{1}, \mathrm{CP}_{2}\right)$.

\begin{tabular}{ccccccccccc}
\hline \multirow{2}{*}{ Tratamentos } & $\mathrm{N}$ & $\mathrm{P}$ & $\mathrm{K}$ & $\mathrm{Ca}$ & $\mathrm{Mg}$ & $\mathrm{S}$ & $\mathrm{Fe}$ & $\mathrm{Mn}$ & $\mathrm{Cu}$ & $\mathrm{Zn}$ \\
\cline { 2 - 10 } & \multicolumn{9}{c}{$\mathrm{g} \mathrm{kg}^{-1}$} \\
$\mathrm{SS}_{0}$ & $25,27^{(1)}$ & $2,40 \mathrm{~b}$ & $5,18 \mathrm{~b}$ & 1,60 & 0,99 & 1,82 & 149,0 & 75,7 & 8,5 & 133,3 \\
$\mathrm{SS}_{1}$ & 24,51 & $2,48 \mathrm{ab}$ & $6,32 \mathrm{a}$ & 1,60 & 0,92 & 1,68 & 143,0 & 69,5 & 7,3 & 126,0 \\
$\mathrm{SS}_{2}$ & 25,60 & $2,70 \mathrm{a}$ & $6,37 \mathrm{a}$ & 1,59 & 1,00 & 1,67 & $141,3 \mathrm{a}$ & 69,5 & 5,3 & 129,0 \\
& & & & & & & & & & \\
$\mathrm{CP}_{0}$ & 25,03 & 2,56 & $6,08 \mathrm{~A}$ & 1,60 & 1,01 & 1,69 & 139,3 & 69,3 & 6,2 & 122,7 \\
$\mathrm{CP}_{1}$ & 25,64 & 2,50 & $5,60 \mathrm{~A}$ & 1,59 & 0,93 & 1,74 & 142,0 & 72,7 & 7,8 & 129,0 \\
$\mathrm{CP}_{2}$ & 25,38 & 2,52 & $6,19 \mathrm{~A}$ & 1,61 & 0,97 & 1,75 & 152,0 & 72,7 & 7,2 & 136,7 \\
\hline C.V. $(\%)$ & 7,40 & 11,27 & 11,36 & 2,80 & 10,49 & 16,51 & 10,59 & 15,57 & 50,45 & 11,82 \\
\hline
\end{tabular}

${ }^{1}$ Médias seguidas da mesma letra nas colunas dentro de cada tratamento não diferem pelo teste Tukey a $5 \%$. 
Tabela 5. Correlação simples ( $r$ ) entre os teores de nutrientes e a massa seca da folha bandeira, entre os teores de nutrientes e a massa de 1000 grãos e entre o teor de nutriente na folha bandeira e nos grãos de aveia-preta cv. Comum do experimento de doses de superfosfato simples e cloreto de potássio.

\begin{tabular}{|c|c|c|c|c|c|c|c|c|c|c|c|}
\hline Características & $\mathrm{N}$ & $\mathrm{P}$ & K & $\mathrm{Ca}$ & $\mathrm{Mg}$ & S & $\mathrm{Fe}$ & $\mathrm{Mn}$ & $\mathrm{Cu}$ & $\mathrm{Zn}$ & B \\
\hline & \multicolumn{11}{|c|}{ Teor na folha bandeira } \\
\hline $\begin{array}{l}\text { Massa seca da } \\
\text { folha bandeira }\end{array}$ & 0,19 & $0,42 * *$ & 0,29 & $0,68 * * *$ & $0,51^{* * *}$ & $0,70^{* * *}$ & $0,54 * *$ & $0,86^{* * *}$ & $0,51 * * *$ & 0,07 & 0,20 \\
\hline \multicolumn{12}{|c|}{ Teor nos grãos } \\
\hline $\begin{array}{l}\text { Massa de } \\
1000 \text { grãos }\end{array}$ & $-0,40^{* *}$ & $0,34^{*}$ & $0,35^{*}$ & $-0,14$ & 0,07 & $-0,01$ & 0,14 & $-0,41^{* *}$ & 0,02 & $0,35^{*}$ & - \\
\hline \multirow{2}{*}{ Folha X grãos } & $\mathrm{NxN}$ & $\mathrm{P} \times \mathrm{P}$ & $\mathrm{KxK}$ & $\mathrm{Ca} \times \mathrm{Ca}$ & $\mathrm{Mg} \times \mathrm{Mg}$ & $\mathrm{S} \times \mathrm{S}$ & $\mathrm{Fe} \times \mathrm{Fe}$ & $\mathrm{Mn} \times \mathrm{Mn}$ & $\mathrm{Cu} \times \mathrm{Cu}$ & $\mathrm{Zn} \times \mathrm{Zn}$ & \\
\hline & $0,39 *$ & $0,53^{* * *}$ & 0,07 & 0,01 & $-0,03$ & $-0,05$ & $-0,01$ & $-0,10$ & 0,01 & 0,11 & \\
\hline
\end{tabular}

$*, * *, * * *$ significativos, respectivamente, a $5 \%, 1 \%$ e $0,1 \%$ de probabilidade pelo teste $\mathrm{t}$.

Considerando que a massa de 1000 grãos foi maior na presença do superfosfato simples (Tabela 3), acompanhada pelo aumento de 51,9\% na produtividade (NAKAGAWA; CAVARIANI; BICUDO, 2003), pode-se inferir que houve maior absorção e ou translocação dos nutrientes para os grãos nos tratamentos que receberam a adubação fosfatada $\left(\mathrm{SS}_{1}\right.$ e $\left.\mathrm{SS}_{2}\right)$ para se ter teores semelhantes ou superiores (Tabela 4), indicando o acúmulo maior (P e K). A correlação obtida entre a massa de 1000 grãos e os teores de $\mathrm{P}$ e $\mathrm{K}$ que responderam a adubação fosfatada, confirmam a eficiência nestes acúmulos. Alguns nutrientes, como $\mathrm{N}, \mathrm{Mn}$ e $\mathrm{Zn}$ apresentaram correlação negativa com a massa de 1000 grãos indicando que para estes o acúmulo de massa foi inverso ao do nutriente.

Comparando os teores de nutrientes dos grãos (Tabela 4) com os apresentados em Welch (1995), verifica-se que os de $\mathrm{P}$ estão abaixo dos relatados $\left(2,9\right.$ a $\left.5,9 \mathrm{~g} \mathrm{~kg}^{-1}\right)$; os de $\mathrm{K}\left(3,1\right.$ a $\left.6,5 \mathrm{~g} \mathrm{~kg}^{-1}\right)$ e os de Ca $\left(0,7\right.$ a $\left.1,8 \mathrm{~g} \mathrm{~kg}^{-1}\right)$ estão dentro; os de $\mathrm{Mg}$ próximos $\left(1,0\right.$ a $\left.1,8 \mathrm{~g} \mathrm{~kg}^{-1}\right)$; os de Fe (60 a $\left.300 \mathrm{mg} \mathrm{kg}^{-1}\right)$, os de Mn (22 a $200 \mathrm{mg} \mathrm{kg}^{-1}$ ) e de Cu estão dentro (3 a $\left.15 \mathrm{mg} \mathrm{kg}^{-1}\right)$ e os de $\mathrm{Zn}$ acima da faixa considerada adequada (21 a $70 \mathrm{mg} \mathrm{kg}^{-1}$ ). Embora as diferenças edafoclimáticas entre experimentos, é interessante observar que para o $\mathrm{P}$ apesar da adubação fosfatada ter incrementado os teores, não foi suficiente para colocá-los nos níveis relatados por Welch (1995), enquanto os teores de $\mathrm{K}$ mantiveram-se dentro dos níveis, apesar do aumento com a adubação fosfatada.

Pelos valores dos coeficientes de correlação simples entre os teores dos nutrientes da folha bandeira com os teores dos mesmos nutrientes dos grãos (Tabela 5), verifica-se que penas para $\mathrm{N}$ e $\mathrm{P}$ foram significativos. Assim, inferere-se que os teores destes elementos nos grãos podem ter recebido contribuição da remobilização das folhas. Peterson, Schrader e Youngs (1974), constataram que quantidades significativas de $\mathrm{P}$ foram remobilizados das folhas e hastes para as panículas em desenvolvimento, enquanto que $\mathrm{Ca}$ e $\mathrm{Mg}$ acumularam continuamente nas panículas sem haver declíneo em outras partes da planta; o $\mathrm{K}$ acumulado nas hastes apresentou pequeno movimento para as panículas; o $\mathrm{Zn}$ das folhas e hastes foi remobilizado para as panículas, enquanto que Fe e Mn acumulados nas panículas não sofreram interferência das concentrações nas folhas e hastes.

Com exceção ao $\mathrm{N}$ e o $\mathrm{P}$, para os demais nutrientes que não apresentaram correlação significativa entre teor na folha bandeira e nos grãos (Tabela 5), podese inferir que o acúmulo nos grãos deve ter ocorrido sem depender da remobilização desses nutrientes das folhas, por serem pouco móveis (MALAVOLTA; VITTI; OLIVEIRA, 1989; PETERSON, 1992). Já para $\mathrm{N}$ e $\mathrm{P}$, os teores na folha bandeira poderão ser indicativos dos teores nos grãos. 
Os teores de $\mathrm{P}, \mathrm{Mg}$, $\mathrm{Cu}$ e $\mathrm{Zn}$ na folha bandeira da aveia-preta localizaram-se nas faixas consideradas adequadas de concentração, que são utilizadas como base para diagnose foliar para aveia-branca (CANTARELLA; RAIJ; CAMARGO, 1996). Esta situação mostra a necessidade da realização de outros trabalhos para verificar se as discrepâncias observadas para os demais nutrientes foram devidos ao experimento ou à características da espécie e cultivar.

\section{Conclusões}

Os teores de $\mathrm{Ca}, \mathrm{Mg}, \mathrm{S}, \mathrm{Fe}, \mathrm{Mn}, \mathrm{Cu}$ e $\mathrm{Zn}$ da folha bandeira e de $\mathrm{P}$ e $\mathrm{K}$ dos grãos de aveia preta foram favorecidos pela adubação fosfatada.

A adubação potássica não influenciou os teores de macro e micronutrientes da folha bandeira e dos grãos em aveia preta.

\section{Referências}

BRASIL. Ministério de Agricultura e Reforma Agrária. Regras para análise de sementes. Brasília: SNDA/ DNDV/CLV, 1992.

CANTARELlA, H.; RAIJ, B. V.; CAMARGO, C. E. O. Cereais. In: RAIJ, B. V.; CANTARELLA, H.; QUAGGIO, J. A.; FURLANI, A. M. C. Recomendações de adubação e calagem para o Estado de São Paulo. Campinas: Instituto Agronômico; Fundação IAC, 1996. p. 45-47. (Boletim Técnico, 100).

CECCON, G.; GRASSI FILHO, H.; BICUDO, S. J. Rendimento de grãos de aveia-branca (Avena sativa L.) em densidades de plantas e doses de nitrogênio. Ciência Rural, Santa Maria, v. 34, n. 6, p. 1723-1729, 2004.

DERPSCH, R.; CALEGARI, A. Plantas para adubação verde de inverno. Londrina: IAPAR, 1992. (Circular IAPAR, 73).

FORSBERG, R. A.; REEVES, D. L. Agronomy of oats. In: WELCH, R.W. The oat crop: production and utilization. London: Chapman \& Hall, 1995. p. 223-251.

KELLING, K. A.; FIXEN, P. E. Soil and nutrient requirements for oat production. In: MARSHALL, H. G.; SORRELLS, M. E. Oat science and technology. Madison: American Society of Agronomy; Crop Science Society of America, 1992. p. 165-190.
MALAVOLTA, E.; VITTI, G. C.; OLIVEIRA, S. A. Avaliação do estado nutricional das plantas: princípios e aplicações. Piracicaba: Associação Brasileira para Pesquisa da Potassa e do Fosfato, 1989.

NAKAGAWA, J.; CAVARIANI, C.; BICUDO, S. J. Adubação nitrogenada, fosfatada e potássica em aveiapreta. Cultura Agronômica, Ilha Solteira, v. 12, n. 1, p. 125-141, 2003.

NAKAGAWA, J.; CAVARIANI, C.; MACHADO, J. R. Adubação nitrogenada no perfilhamento da aveia-preta em duas condições de fertilidade do solo. Pesquisa Agropecuária Brasileira, Brasília, v. 35, n. 6, p. 17011080, 2000.

Efeitos da dose e da época de aplicação de $\mathrm{N}$ na produção e qualidade de sementes de aveia-preta. Científica, São Paulo, v. 23, n. 1, p. 31-43, 1995.

NAKAGAWA, J.; ROSOLEM, C. A. Teores de nutrientes na folha e nos grãos de aveia-preta em função da adubação com fósforo e potássio. Bragantia, Campinas, v. 64, n. 3 , p. 441-445, 2005.

OLIVEIRA, J. B.; CAMARGO, M. N.; ROSSI, M.; CALDERON FILHO, B. Mapa pedológico do Estado de São Paulo: legenda expandida. Campinas: Instituto Agronômico; Rio de Janeiro: EMBRAPA - Solos, 1999.

PETERSON, D. M. Physiology and development of the oat plant. In: MARSHALL, H.G.; SORRELLS, M.E. Oat science and technology. Madison: American Society of Agronomy; Crop Science Society of America, 1992. p. 77-114.

PETERSON, D. M.; SCHRADER, L. E.; YOUNGS, V. L. Elemental composition of developing oat plants. Crop Science, Madison, v. 14, n. 5, p. 735-739, 1974.

PRIMAVESI, A. C. P. A.; PRIMAVESI, O. Avaliação do potencial de resposta ao nitrogênio sob regimes de corte, de dois cultivares de aveia. I. Produção de forragem e de grãos. Revista de Agricultura, Piracicaba, v. 71, n. 1, p. 105-118, 1996.

RAIJ, B., V.; CANTARElla, H.; QUAGGIO, J. A.; FURLANI, A. M. C. Recomendações de adubação e calagem para o Estado de São Paulo. 2. ed. Campinas: Instituto Agronômico; Fundação IAC, 1996. (Boletim Técnico, 100).

RAIJ, B., V.; QUAGGIO, J.A. Métodos de análise de solo para fins de fertilidade. Campinas: Instituto Agronômico, 1983. (Boletim técnico, 81).

RODRIGUES, A. N. A.; VOLKWEISS, S. J.; ANGHINONI, I. Efeitos imediatos e residuais do superfosfato triplo sobre o rendimento de matéria seca e absorção de fósforo por aveia forrageira em solo Podzólico 
Vermelho-Escuro. Revista Brasileira de Ciência do Solo, Campinas, v. 9, n. 3, p. 219-224, 1985.

SCHUCH, L. O. B.; NEDEL, J. L.; MAIA, M. S.; ASSIS, F. N. Vigor de sementes e adubação nitrogenada em aveia-preta (Avena strigosa Schreb.). Revista Brasileira de Sementes, Brasília, v. 21, n. 2, p. 127-134, 1999.

SILVA, R. H.; ZUCARELI, C.; NAKAGAWA, J.; SILVA, R. A., CAVARIANI, C. Doses e épocas de aplicação do nitrogênio na produção e qualidade de sementes de aveiapreta. Revista Brasileira de Sementes, Brasília, v. 23, n. 2, p. 51-55, 2001.
WELCH, R. W. The chemical composition of oats. In: WELCH, R. W. The oat crop:production and utilization. London: Chapman \& Hall, 1995. p. 279-320.

WUTKE, E. B. Adubação verde: manejo da fitomassa e espécies utilizadas no Estado de São Paulo. In: WUTKE, E. B.; BULISANI, E. A.; MASCARENHAS, H. A. A. I Curso sobre adubação verde no Instituto Agronômico. Campinas: Instituto Agronômico, 1993. p. 17-29. 